\title{
Non-alcoholic Fatty Liver Disease in Children: An emerging Public health problem in India
}

Aayushi Rastogi ${ }^{1}$, Umesh Kapil ${ }^{2}$

${ }^{1}$ MSc. Clinical Research, J.R.F and Ph.D. Scholar, Department of Epidemiology, Institute of Liver and Biliary Sciences; ${ }^{2} \mathrm{MD}$, Community Medicine, Professor, Department of Epidemiology, Institute of Liver and Biliary Sciences.

\begin{tabular}{|c|c|c|c|c|c|c|c|}
\hline Abstract & Introduction & Methodology & Results & Conclusion & References & Citation & Tables / Figures \\
\hline \multicolumn{8}{|c|}{ Corresponding Author } \\
\hline \multicolumn{7}{|c|}{$\begin{array}{l}\text { Ms Aayushi Rastogi, Department of Epidemiology, Institute of Liver and Biliary Sciences, New Delhi. } \\
\text { E Mail ID: } \underline{\text { rastogiaayushi6@gmail.com }}\end{array}$} & 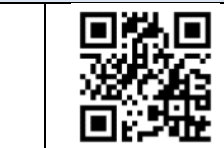 \\
\hline
\end{tabular}

\section{Citation}

Rastogi A, Kapil U. Non-alcoholic Fatty Liver Disease in Children: An emerging Public health problem in India. Indian J Comm Health. 2020;32(2):330 - 336.

Source of Funding: Nil Conflict of Interest: None declared

\section{Article Cycle}

Received: 23/05/2020; Revision: 30/05/2020; Accepted: 10/06/2020; Published: 30/06/2020

This work is licensed under a Creative Commons Attribution 4.0 International License.

\section{Abstract}

NAFLD was earlier believed to be the disease of adults only however in 1983, the existence of this disease was seen in paediatric population. Nearly four decades have passed since the first description of the Paediatric NAFLD (P-NAFLD), yet it is one of the areas which is given least priority in the country. The P-NAFLD is reversible and can be prevented by lifestyle and behaviour modification and hence there is a need to this review highlights the importance of P-NAFLD in the country and need for formulating strategies for prevention and control of P-NAFLD in the country. All published articles in the MEDLINE database on P-NAFLD in India were included. The important findings were summarized and critically analysed. The existing review suggests, the prevalence of P-NAFLD is uncertain in the country. NAFLD is a phenotypic product of complex interaction of heredity (nature) and environment (nurture). This review summarizes the importance of P-NAFLD in India and discusses the predisposition of these risk factors in Indian children. Further population-based studies on prevalence and incidence are required on general paediatric population to quantify the magnitude of the disease in India for better management of the condition.

\section{Keywords}

Non-alcoholic Fatty Liver Disease; Child; Adolescent; Epidemiology; Metabolic Syndrome; Obesity; Diabetes Mellitus

\section{Key Message}

P-NAFLD is likely to become the most overwhelming cause of liver diseases. P-NAFLD is associated with several hepatic manifestations. These co-morbidities are expensive to manage with limited possibilities at later stages. It is potentially reversible at early stage through lifestyle modifications and public health intervention strategies are required in India.

\section{Introduction}

Non-alcoholic fatty liver disease in adults (A-NAFLD) is a form of chronic liver disease which is commonly defined as the accumulation of fat in the liver in the absence of significant alcohol consumption and ruling out other known liver pathologies (1). NAFLD consists of a wide spectrum of diseases ranging from infiltration of fat into the liver (steatosis) to hepatocellular inflammation (Nonalcoholic Steatohepatitis-NASH) to fibrosis and eventually to cirrhosis(2).

At the global level, it is estimated that the prevalence of A-NAFLD in general population is $25 \%$ with regional differences varying from $14 \%$ in Africa to $32 \%$ in Middle
East countries(3,4).The prevalence of the A-NAFLD and NASH has been to be escalating with the parallel increase in obesity, Type 2 Diabetes (T2DM) and Metabolic Syndrome (MetS) and is expected to become the leading cause of liver transplantation in coming years(5).

NAFLD was earlier believed to be the disease of adults but in early 1980s, the existence of this hepatic disease was documented in paediatric population (P-NAFLD)(6). The mean global prevalence of P-NAFLD from general population based studies has been reported to be $7.6 \%(7)$. These prevalence estimates in children from the general population reported may not represent the 'true estimates' as there are limited number of studies. 
It is difficult to assess P-NAFLD accurately because of absence of simple and non-invasive diagnostic tests. The 'gold standard' for diagnosing the disease is a liver biopsy, but this is neither feasible nor ethical to use in apparently healthy and asymptomatic children.

Nearly four decades have passed since the documentation of the P-NAFLD, yet it has not been accorded priority for public health intervention management in world as well as in India. The present review is aimed at highlighting the magnitude of P-NAFLD and its health consequences and need for future efforts to be taken to address this public health problem.

\section{Aims \& Objectives}

1. Highlight the magnitude of P-NAFLD in India.

2. Study the risk factors and health consequences associated with P-NAFLD.

\section{Material \& Methods}

Literature search was performed in the online Medline database (Medical Literature Analysis and Retrieval System) using MeSH (Medical Subject Headings) term: 'Non-alcoholic Fatty Liver Disease'. The above results were further narrowed down by adding the MeSH term related to 'Adolescent' and 'Child' in the search strategy. The search was limited to Indian studies published in English language. In addition to this, google search with key terms was also performed. We accessed full text articles of the included studies (8-19).

\section{Results}

\section{Magnitude of P-NAFLD in India}

The prevalence of NAFLD in Indian children is uncertain as limited studies are available (Figure 1). A study on Kashmiri children with mean age of $13.4 \pm 3.8$ years stated the prevalence of $7.4 \%(18)$. There are few studies by independent researchers across the country in obese population (average prevalence is approximately 60\%). These studies have documented approximately twice the prevalence of NAFLD when compared to the global obese paediatric population (approximately 34\%(7). A study from Mumbai (2016) has reported a prevalence of $62 \%$ in overweight and obese children(16). Another study from North Kerala stated a prevalence of $60 \%$ in overweight and obese children(17). A recent study from Delhi (2018) has reported similar prevalence $(62.5 \%)$ estimates in obese adolescents(19). A study on 961 north Indian urban school pre-adolescence (children aged 5-10 year) reported the prevalence as $22.4 \%$ (15).

Another study on children aged 5-12 years with a sample size of 100 quoted the prevalence of $3 \%$, diagnosing modality being Ultrasound(10). With the limited studies, it difficult to estimate the true prevalence of NAFLD in children in community as most of the studies have been conducted in obese children or in selective age groups.

\section{Risk factors}

[Non-alcoholic Fatty...] | Rastogi A et al

The evidence generated over the years from the liver biopsies of patients suggests that the progression of NAFLD from steatosis to NASH is not following linear curve rather it is more dynamic and exponential as the stage of fibrosis increases. Furthermore, these fibrosis rates vary from person to person. This indicates that NAFLD is a complex disorder affected by interaction of environmental and genetic factors which eventually determine the manifestation of NAFLD and its progression(20,21,22). Moreover, twins and family based studies have pointed towards NAFLD as a heritable manifestation, with a heritability ranging from $22 \%$ to $38 \%(23,24,25)$.

The genetic predisposition plays a major role in the causation of the P-NAFLD, but environmental factors like dietary habits, physical activity, microbiota and metabolic disease of the individual child are important determinants and can't be overlooked(26).

1. Genetic associations with P-NAFLD: To date, several genome-wide association studies (GWAS) and many associations between single nucleotide polymorphisms (SNPS) and NAFLD have led to identification of novel loci associated with disease phenotypes. However, non- synonymous SNPs in two genes - C>G SNP in PNPLA3 and C>T SNP in TM6SF2 have been exclusively found to be consistently increasing the risk of NAFLD, despite significant differences within the ethnicities in India $(27,28)$. Though we don't have data on Paediatric population but similar findings can be extrapolated to the paediatrics as the genetic material remains the same

2. Role of epigenetic factors: Epigenetic changes are relatively stable alterations particularly caused by methylation of cytosine nucleotides at CpG-rich regulatory or promoter regions and several posttranslational histone modifications in transcription and regulatory factors of genetic material.

Epigenetic regulation demonstrated by non-coding RNAs (miRNAs) and the effect of intrauterine exposure to a high-fat diet have shown to have more severe hepatic fat accumulation and development of $\mathrm{NASH}$ in the offspring in experimental models $(29,30)$. Thus, these epigenetic changes can be transmitted through cell division, thereby they explain the mechanism through which effect of environmental exposures on phenotype.

3. Role of environmental factors: Role of genetics and hereditary causation should be positioned in the framework of environmental factors that have an indispensable role to play in development of the disease and severity associated with it. The most important factors are dietary habits, physical activity and clinical profile of the individual. 
3.1. Diet, Physical Activity and P-NAFLD: Excess energy intake due to fast-foods, meals eaten out, and fried foods can influence the liver function and markedly, result in increase in body weight and P-NAFLD. Furthermore, inappropriate patterns of food consumption, including the habit of missing breakfast, eating too much during evening meals, eating at night, and eating too rapidly, are often certain practices associated with P-NAFLD(31). A study aimed at studying the nutritional risk factor in P-NAFLD in Indian setting suggested higher intake of total calorie, carbohydrate and fats when compared to non-NAFLD controls(32). A study from Punjab on Paediatric group stated daily consumption of soft drinks $(60.4 \%)$ and fried chips (58.5\%) were more in P-NAFLD group than non-NAFLD group(14). A study from tertiary care hospital quoted that children with increased BMI consumed more junk food and beverages when compared to children with normal $\mathrm{BMI}$ and are more likely to have fatty liver disease ( $p$ $<0.001)(33)$. In another study dietary habits weren't found to be significant, mainly attributable to lapses in weekly recall of history and smaller sample size(16). The existing data suggests that dietary structure predisposes individuals particularly in PNAFLD.

In addition to these dietary habits, individuals with fatty liver were found to have very low physical activity levels and increased sitting times compared with healthy children. Overindulgence in indoor leisure activities like watching television, surfing internet and playing mobile and computer games) alone or in combination with other circumstances like lack of open spaces and playgrounds in schools and communities along with increasing pressure to excel in academics and reduced emphasis on sports has led to decline in physical activity and elevated the sedentary lifestyle $(31,32,33)$.

3.2. Age and P-NAFLD: The prevalence of NAFLD increases as the child moved from childhood to adulthood via adolescence. The prevalence of fatty liver increased with age in both boys and girls, from $13.1 \%$ in $5-6$ years to $31 \%$ in $9-10$ years agegroup(15). Moreover, as the child grows, more exposure to environmental changes may also contribute to the high prevalence of P-NAFLD.

3.3. Gender and P-NAFLD: Evidence from animal and human studies have supported the concept that female sex is safeguarded from dysmetabolic traits, specifically because of oestrogen which is in traces in opposite sex. Premenopausal women are equally protected from developing NAFLD as menopausal women(34). Similar results have been obtained from the existing studies. P-NAFLD is approximately 50\% more common in boys(OR $1.5 ; 95 \% \mathrm{Cl} 1.3-1.8$ ) than in girls(15).
3.4. Obesity and P-NAFLD: The prevalence of P-NAFLD is also related to clinical profile of the individual. Numerous studies have demonstrated a direct association between P-NAFLD and body mass index (BMI), with higher disease burdens in heavier patients. Pooled data from Indian studies performed mainly in adolescents, the prevalence of P-NAFLD in over-weight and obese children ranges from $29 \%$ to $88 \%$.

It has been documented that P-NAFLD was absent in underweight children but a high proportion of normal-weight children also had NAFLD and along with metabolic derangements(15). As these data indicate, it is important to recognize that NAFLD may also occur in normal-weight children, though less frequently than in overweight and obese group.

3.5. Metabolic Parameters and NAFLD: Insulin resistance is undoubtedly associated with P-NAFLD and its progression irrespective of the age of individual. Multiple studies have exposed raised fasting insulin levels and reduced insulin sensitivity in children as culprits for developing NAFLD. Higher prevalence of hyperinsulinemia (50\%) in the children with P-NAFLD but without diabetes and hypothyroidismre-emphasizes the role of insulin resistance role in fatty liver (35).

P-NAFLD has been intensely associated with several components of the MetS, including obesity, dyslipidaemia hypertension, particularly insulin resistance. Due to overlap of the various parameters with MetS and P-NAFLD, it is believed, NAFLD is the hepatic manifestation of the MetS.

P-NAFLD has not been left untouched by the MetS(33). The children with NAFLD have shown to have more co-morbidities than non-NAFLD children. A study on pre-adolescent group having fatty liver showed approximately $10 \%$ prevalence of hypertension, hyperglycemia in $12 \%$, hypertriglyceridemia in $24 \%$, Low HDL in $38.5 \%$ and metabolic syndrome in $8 \%(15)$. As high as $56 \%$ of prevalence of metabolic syndrome have been reported across the country in children with PNAFLD(36).

The above evidence suggests that NAFLD is a phenotypic product of complex interaction of heredity (nature) and environment (nurture) (Figure 2).

Health consequences

There is paucity of studies describing clinical experience with children having NASH, which is the progressed form of the P-NAFLD disease. Few studies with small sample size have documented the stages of fibrosis as mild in $42 \%$, moderate in $34 \%$ and severe steatosis in $24 \%$ of biopsies(37). A multi-centric study among biopsy-proven P-NAFLD, cases suggested advanced fibrosis or cirrhosis in 
approximately $24 \%$ of cases with average age of 13 years at the time of diagnosis (38).

A retrospective longitudinal hospital-based study with 20 years of follow-up depicted that children with NAFLD had 13.8 times higher risk of dying or require a liver transplantation than the general population of the same age and sex. In addition, to this progression of fibrosis stage was documented in four cases out of five cases studied, seen as early as 7 months to as late as 82 months after diagnosing of P-NAFLD. Moreover, the most notable and concerning findings of the study was, two children died and two underwent liver transplantation for decompensated cirrhosis during the follow up(39).

NAFLD is a rising cause of hepatocellular carcinoma (HCC) in adults whereas the incidence of $\mathrm{HCC}$ in children with NAFLD is yet to be investigated. A case-report of a 7-yearold obese male described the occurrence of HCC with NAFLD in 2014(40). Though, HCC is rare but having NAFLD in early age may serve as an important risk factor for HCC in adulthood. The HCC in paediatric NAFLD cases is uncommon but have the potential to burden the early adulthood in future.

In addition to hepatic outcomes, P-NAFLD is found to be associated with morbidities associated with psychosocial, cardiovascular and metabolic parameters.

Though NAFLD is an hidden asymptomatic disease but children with NAFLD have reported many symptoms like irritability (73\%), fatigue (68\%), headache (60\%), trouble in concentrating (55\%) and cramps in muscle (53\%)(41). Psychosocial aspects related to P-NAFLD need further detailed evaluation as it is unclear whether these symptoms arise from the P-NAFLD disease itself or are associated symptoms. In addition, impaired quality of life and higher level of depression has been reported in children with P-NAFLD as compared to controls $(41,42)$. Children from India have also reported signs and/or symptoms like pain abdomen $(6.4 \%)$, jaundice $(2.8 \%)$ or vomiting (2.1\%) (15).

A retrospective study stated that at the time of diagnosis of P-NAFLD only $29 \%$ of the children had metabolic syndrome whereas at least $83 \%$ had one of the components of metabolic syndrome. Over the 20 year follow-up with participants undergoing treatment recommendations, four developed T2DM (4-11 years after diagnosed with P-NAFLD, six patient developed cholecystitis which required cholecystectomy, two patients with morbid obesity required bariatric surgery, one patient developed contraceptive induced liver injury and one patient each developed bilateral oophorectomy and hysterectomy for endometriosis. Furthermore, a biopsy-proven P-NAFLD cases had shown a much higher cardiovascular risk profile (which included total cholesterol, LDL, triglycerides and systolic blood pressure) than children with obesity alone(43). Similar findings have been reported from Indian settings as well. P-NAFLD has been demonstrated to be more frequent in children with metabolic syndrome (56\%) than in those without it(15). A study on obese and overweight children with PNAFLD documented prevalence of hypertension as $6 \%$, dyslipidemia as $18 \%$, T2DM as $2 \%$ and insulin resistance as $66 \%$ (16). In addition to these, AST and ALT levels were found was significantly higher in the P-NAFLD group $(15,16)$.

P-NAFLD is a complex disease which has the potential to cause multi-organ complications and morbidities in future. The cause-and-effect relationship with various complications is still under -investigations. It is yet being investigated which of these complications arise directly as a result of hepatic manifestation and which are associated with the disease via various physiological pathways.

\section{Management of NAFLD}

Weight loss is the only established treatment for P-NAFLD. Numerous studies have shown that weight loss can have substantial long-term benefit with as little as a $5 \%$ to $10 \%$ reduction in body weight. A study suggested 6 months of lifestyle modification, led to improvement of Fibroscan values significantly $(8.31 \pm 0.11 \mathrm{kPa}$ vs $7.87 \pm 0.12 \mathrm{kPa}$, $\mathrm{p}=0.009$ ) resulting in downgrading hepatic injury in PNAFLD patients(44). According to a recent systematic review suggested supervised-exercise including both aerobic and resistance exercise with a volume $\geq 60 \mathrm{~min} / \mathrm{session}$ and a frequency $\geq 3$ sessions/week can significantly reduce hepatic fat content compared to the control groups in adolescent population (6 -19 years)(45). There are no existing recommendations regarding the most efficacious nutritional modifications in children with P-NAFLD. Further, for paediatric group, dietary changes should not compromise with adequate nutrients. Exclusion of saturated fats, sucrose, and concentrated fructose sweeteners may help in reducing hepatic steatosis. This permits a low-calorie diet comprised of wholegrains, vegetables, fruits, dietary proteins, and some fats. A well-balanced diet in combination with moderate physical activity is probably the most efficacious approach to weight loss and resolution of steatosis(46). Therefore, lifestyle intervention programs based on increasing physical activity levels, improving dietary habits, and promoting a healthy weight are more preferred in adolescents, since that they have preserved capacity to exercise and fewer comorbidities. However, limited evidence due to paucity of studies inhibits the recommendation of any specific dietary and/or lifestyle strategies for clinical practices. Until high-quality evidence emerges that support specific interventions with additional clinical benefit, general healthy eating and physical activity guidelines and promoting weight loss, remains first-line treatment(47).

\section{Way forward}

India was once infamous for under-nutrition but now it has become the land of obesity with the prevalence of overweight and obesity among men and women has doubled in last two decades from 1998-99 to 2015-16(48). 
The pooled data from 52 studies across 16 states of India estimated a mean prevalence of childhood overweight and obesity to be $19.3 \%$. The combined prevalence has significantly increased from the earlier reported prevalence of $16.3 \%$ in 2001-2005(49). The health consequences of childhood overweight/obesity include hyperlipidemia, hypertension, T2DM, sleep apnea, degenerative joint disease, and chronic renal dysfunction. P-NAFLD can be added to the long list of adverse complications. With increasing domain of childhood obesity, P-NAFLD is also expanding its boundaries and rapidly becoming one of the most important chronic liver diseases in children. Thus, P-NAFLD is a growing public health concern. Moreover, unattended and untreated burden of P-NAFLD will enter the adulthood resulting in rise of chronic liver disease resulting in cirrhosis and hepatocellular carcinoma at much early age. The preventive steps addressed during childhood will not only reverse the damage caused by fibrosis of liver but will also promote healthy growth of the individual(44). The lifestyle changes are aimed at weight reduction which can be achieved by escalating the physical exercise along with dietary modification. Furthermore, first line treatment for P-NAFLD is inexpensive but has the capacity to prevent expensive medical procedures like liver transplantation at later stage which are not only complicated but also has low success rates. Hence, the NALFD in children is a public health concern and needs immediate attention by the policy makers and health departments.

There is paucity of data from Indian settings hence, there is an urgent need to undertake meticulously planned national study in children representing each and every age group from various ethnic regions, to document the magnitude NAFLD in the country to draw attention of health managers and policy makers in the country for the formulation of public health interventions.

\section{Conclusion}

The prevalence of P-NAFLD ranges from $7 \%$ to $70 \%$ in Indian setting, however with limited data, it difficult to estimate the true prevalence of P-NAFLD in community as most of the studies have been conducted in obese children or in selective age groups. Hence there is an urgent need to undertake meticulously planned national study in children representing each and every age group from various ethnic regions, to document the magnitude and risk factors associated with NAFLD in the country. The high burden of P-NAFLD will itself draw attention of health managers and policy makers in the country for the formulation of public health interventions.

\section{Recommendation}

P-NAFLD is likely to become the most overwhelming cause of liver diseases in Indian sub-continent in coming years. The present limited evidence indicates that P-NAFLD is not just confined to liver-specific morbidity and mortality, but also associated with numerous extra-hepatic manifestations, such as cardiovascular diseases, chronic renal diseases, and metabolic diseases. These comorbidities are expensive to manage with limited possibilities at later stages. The P-NAFLD is potentially reversible and preventable at early stage through lifestyle and behaviour modifications and we need to develop public health intervention strategies in India.

\section{Limitation of the study}

The studies published in English language in PubMed and google search were included in this review. Studies published in other databases and in other languages have not been considered for the review.

\section{Relevance of the study}

There is limited evidence with regards to Paediatric NAFLD in India. This is the first article describing the prevalence of NAFLD in children and risk factors associated with it in India.

\section{Authors Contribution}

UK: conceptual ideas and proof outline. AR: all of the technical details, and performed the literature search for the existing review, lead writing manuscript and UK supervised manuscript and contributed to the final version of manuscript.

\section{Acknowledgement}

This work is supported by Grant from Indian Council of Medical Research (ICMR), New Delhi, India. Aayushi Rastogi gratefully acknowledges ICMR for Junior Research Fellowship (no: 3/1/3/JRF-2018/HRD-053 (65377)).

\section{References}

1. Bellentani S, Marino M. Epidemiology and natural history of nonalcoholic fatty liver disease (NAFLD). Ann Hepatol. 2009;8 Suppl 1:S4-8. Review. PubMed PMID: 19381118.[PubMed].

2. Jou J, Choi SS, Diehl AM. Mechanisms of disease progression in nonalcoholic fatty liver disease. Semin Liver Dis. 2008 Nov;28(4):370-9. doi: 10.1055/s-0028-1091981. Epub 2008 Oct 27. Review. PubMed PMID: 18956293.[PubMed].

3. Younossi Z, Anstee QM, Marietti M, Hardy T, Henry L, Eslam M, George J, Bugianesi E. Global burden of NAFLD and NASH: trends, predictions, risk factors and prevention. Nat Rev Gastroenterol Hepatol. 2018 Jan;15(1):11-20. doi: 10.1038/nrgastro.2017.109. Epub 2017 Sep 20. Review. PubMed PMID: 28930295.[PubMed].

4. Araújo AR, Rosso N, Bedogni G, Tiribelli C, Bellentani S. Global epidemiology of non-alcoholic fatty liver disease/non-alcoholic steatohepatitis: What we need in the future. Liver Int. 2018 Feb;38 Suppl 1:47-51. doi: 10.1111/liv.13643. Review. PubMed PMID: 29427488.[PubMed].

5. Pais R, Barritt AS 4th, Calmus $Y$, Scatton $O$, Runge $T$, Lebray $P$, Poynard T, Ratziu V, Conti F. NAFLD and liver transplantation: Current burden and expected challenges. J Hepatol. 2016 Dec;65(6):1245-1257. doi: 10.1016/j.jhep.2016.07.033. Epub 2016 Jul 30. Review. PubMed PMID: 27486010; PubMed Central PMCID: PMC5326676.[PubMed].

6. Moran JR, Ghishan FK, Halter SA, Greene HL. Steatohepatitis in obese children: a cause of chronic liver dysfunction. Am J Gastroenterol. 1983 Jun;78(6):374-7. PubMed PMID: 6859017.[PubMed]

7. Anderson EL, Howe LD, Jones HE, Higgins JP, Lawlor DA, Fraser A. The Prevalence of Non-Alcoholic Fatty Liver Disease in Children and Adolescents: A Systematic Review and Meta-Analysis. PLoS One. 

eCollection 2015. Review. PubMed PMID: 26512983; PubMed Central PMCID: PMC4626023.[PubMed]

8. Sathiyasekaran M, Shabeer MM, Bavanandam S. Non Alcholic Fatty Liver Disease (NAFLD) in Overweight and Obese Children. Journal of Clinical and Experimental Hepatology. 2014 Mar 1;4:S35.

9. Ghanghoriya P, Mandraha S, Mishra CK. Prevalence of nonalcoholic fatty liver disease and its correlation with anthropometric measures and laboratory parameters in overweight and obese children and adolescents. Indian Journal of Child Health. 2018 Jun 5;359-62.

10. Chaturvedi K, Vohra P. Non-alcoholic fatty liver disease in children. Indian Pediatr. 2012 Sep;49(9):757-8. doi: 10.1007/s13312-012 0161-y. PubMed PMID: 23024085.[PubMed].

11. Study of Family Clustering and PNPLA3 Gene Polymorphism in Pediatric Non Alcoholic Fatty Liver Disease [Internet]. [cited 2020 Apr 16]. Available from: http://www.indianpediatrics.net/july2018/july-561-567.htm

12. Correlation between metabolic, liver profile, dietary habits and ultrasound scan determined non-alcoholic fatty liver disease changes in children aged 6-18 years with body mass index [Internet]. [cited 2020 Apr 16]. Available from: https://sljch.sljol.info/articles/abstract/10.4038/sljch.v47i2.8477/

13. Parry IA, Bhat RA, Khan I. The Prevalence of Non-alcoholic Fatty Liver Disease and its Association with Metabolic Syndrome and Obesity in Pediatric Population of North India [Internet]. 2013 [cited 2020 Apr 12]. Available from: https://www.semanticscholar.org/paper/The-Prevalence-of-Nonalcoholic-Fatty-Liver-Disease-ParryBhat/e359ce72cc8417778da118a54c335496b576ec2b

14. Goyal P, Thapa B, Sharma NR, Menon J, Bhatia A. Nutritional assessment in obese children with and without non-alcoholic fatty liver disease (NAFLD) in an Urban Area of Punjab, India. Ind Jour of Publ Health Rese \& Develop. 2018;9(12):201.

15. Das MK, Sibal A, Bhatia V, Sahu S, Arora NK. Nonalcoholic Fatty Liver Disease in North Indian Children and Association With Metabolic Syndrome: Are Normal-Weight Children Spared? Clinical Gastroenterology and Hepatology. 2014 Jan 1;12(1):163-4.

16. Pawar SV, Zanwar VG, Choksey AS, Mohite AR, Jain SS, Surude RG, Contractor QQ, Rathi PM, Verma RU, Varthakavi PK. Most overweight and obese Indian children have nonalcoholic fatty liver disease. Ann Hepatol. 2016 Nov-Dec 2016;15(6):853-861. doi: 10.5604/16652681.1222101. PubMed PMID: 27740518.[PubMed]

17. G. R, P. M. Prevalence of non-alcoholic fatty liver disease among obese children in North Kerala, India. Int J Contemp Pediatr. 2017 Apr 25;4(3):1051.

18. Ultrasonographic Prevalence of Non-Alcoholic Fatty Liver Disease (Nafld) in Kashmir Valley School Children [Internet]. ResearchGate. [cited 2020 Apr 16]. Available from: https://www.researchgate.net/publication/273221099_Ultrasono graphic_Prevalence_of_Non-

Alcoholic_Fatty_Liver_Disease_Nafld_in_Kashmir_Valley_School_ Children

19. Jain V, Jana M, Upadhyay B, Ahmad N, Jain O, Upadhyay AD, Ramakrishnan L, Vikram NK. Prevalence, clinical \& biochemical correlates of non-alcoholic fatty liver disease in overweight adolescents. Indian J Med Res. 2018 Sep;148(3):291-301. doi: 10.4103/ijmr.IJMR_1966_16. PubMed PMID: 30425219; PubMed Central PMCID: PMC6251268.[PubMed].

20. McPherson S, Hardy T, Henderson E, Burt AD, Day CP, Anstee QM. Evidence of NAFLD progression from steatosis to fibrosingsteatohepatitis using paired biopsies: implications for prognosis and clinical management. J Hepatol. 2015 May;62(5):1148-55. doi: 10.1016/j.jhep.2014.11.034. Epub 2014 Dec 1. PubMed PMID: 25477264. [PubMed].

21. Singh S, Allen AM, Wang Z, Prokop LJ, Murad MH, Loomba R. Fibrosis progression in nonalcoholic fatty liver vs nonalcoholic steatohepatitis: a systematic review and meta-analysis of pairedbiopsy studies. Clin Gastroenterol Hepatol. 2015 Apr;13(4):64354.e1-9; quiz e39-40. doi: 10.1016/j.cgh.2014.04.014. Epub 2014

[Non-alcoholic Fatty...] | Rastogi A et al Apr 24. Review. PubMed PMID: 24768810; PubMed Central PMCID: PMC4208976.[PubMed].

22. Angulo $P$, Kleiner DE, Dam-Larsen $S$, Adams LA, Bjornsson ES, Charatcharoenwitthaya P, Mills PR, Keach JC, Lafferty HD, Stahler A, Haflidadottir S, Bendtsen F. Liver Fibrosis, but No Other Histologic Features, Is Associated With Long-term Outcomes of Patients With Nonalcoholic Fatty Liver Disease. Gastroenterology. 2015 Aug;149(2):389-97.e10. doi: 10.1053/j.gastro.2015.04.043. Epub 2015 Apr 29. PubMed PMID: 25935633; PubMed Central PMCID: PMC4516664.[PubMed].

23. Loomba R, Schork $\mathrm{N}$, Chen $\mathrm{CH}$, Bettencourt R, Bhatt A, Ang B, Nguyen $P$, Hernandez C, Richards L, Salotti J, Lin S, Seki E, Nelson KE, Sirlin CB, Brenner D. Heritability of Hepatic Fibrosis and Steatosis Based on a Prospective Twin Study. Gastroenterology. 2015 Dec;149(7):1784-93. doi: 10.1053/j.gastro.2015.08.011. Epub 2015 Aug 20. PubMed PMID: 26299412; PubMed Central PMCID: PMC4663110. [PubMed].

24. Schwimmer JB, Celedon MA, Lavine JE, Salem R, Campbell N, Schork NJ, Shiehmorteza M, Yokoo T, Chavez A, Middleton MS, Sirlin CB. Heritability of nonalcoholic fatty liver disease. Gastroenterology. 2009 May;136(5):1585-92. doi: 10.1053/j.gastro.2009.01.050. Epub 2009 Jan 25. PubMed PMID: 19208353; PubMed Central PMCID: PMC3397140.[PubMed].

25. Cui J, Chen CH, Lo MT, Schork N, Bettencourt R, Gonzalez MP, Bhatt A, Hooker J, Shaffer K, Nelson KE, Long MT, Brenner DA, Sirlin CB, Loomba R, For The Genetics Of Nafld In Twins Consortium. Shared genetic effects between hepatic steatosis and fibrosis: A prospective twin study. Hepatology. 2016 Nov;64(5):1547-1558. doi: 10.1002/hep.28674. Epub 2016 Jul 25. PubMed PMID: 27315352; PubMed Central PMCID: PMC5090982.[PubMed].

26. Day CP. Genes or environment to determine alcoholic liver disease and non-alcoholic fatty liver disease. Liver Int. 2006 Nov;26(9):1021-8. doi: 10.1111/j.1478-3231.2006.01323.x. Review. PubMed PMID: 17032401.[PubMed]

27. Chatterjee A, Basu A, Chowdhury A, Das K, Sarkar-Roy N, Majumder $P P$, et al. Comparative analyses of genetic risk prediction methods reveal extreme diversity of genetic predisposition to nonalcoholic fatty liver disease (NAFLD) among ethnic populations of India. J Genet. 2015 Mar;94(1):105-13.

28. Bale G, Steffie AU, Ravi Kanth VV, Rao PN, Sharma M, Sasikala M, Reddy DN. Regional differences in genetic susceptibility to nonalcoholic liver disease in two distinct Indian ethnicities. World J Hepatol. 2017 Sep 18;9(26):1101-1107. doi: 10.4254/wjh.v9.i26.1101. PubMed PMID: 28989566; PubMed Central PMCID: PMC5612841.[PubMed].

29. Cheung O, Puri P, Eicken C, Contos MJ, Mirshahi F, Maher JW, Kellum JM, Min H, Luketic VA, Sanyal AJ. Nonalcoholic steatohepatitis is associated with altered hepatic MicroRNA expression. Hepatology. 2008 Dec;48(6):1810-20. doi: 10.1002/hep.22569. PubMed PMID: 19030170; PubMed Central PMCID: PMC2717729.[PubMed].

30. Bruce KD, Cagampang FR, Argenton M, Zhang J, Ethirajan PL, Burdge GC, Bateman AC, Clough GF, Poston L, Hanson MA, McConnell JM, Byrne CD. Maternal high-fat feeding primes steatohepatitis in adult mice offspring, involving mitochondrial dysfunction and altered lipogenesis gene expression. Hepatology. 2009 Dec;50(6):1796-808. doi: 10.1002/hep.23205. PubMed PMID: 19816994.[PubMed].

31. Yasutake K, Kohjima M, Kotoh K, Nakashima M, Nakamuta M, Enjoji $M$. Dietary habits and behaviors associated with nonalcoholic fatty liver disease. World J Gastroenterol. 2014 Feb 21;20(7):1756-67. doi: 10.3748/wjg.v20.i7.1756. Review. PubMed PMID: 24587653; PubMed Central PMCID: PMC3930974.[PubMed]

32. Sathiaraj E, Chutke M, Reddy MY, Pratap N, Rao PN, Reddy DN, Raghunath M. A case-control study on nutritional risk factors in non-alcoholic fatty liver disease in Indian population. Eur J Clin Nutr. 2011 Apr;65(4):533-7. doi: 10.1038/ejcn.2011.3. Epub 2011 Feb 23. PubMed PMID: 21346716. [PubMed]

33. Correlation between metabolic, liver profile, dietary habits and ultrasound scan determined non-alcoholic fatty liver disease 
INDIAN JOURNAL OF COMMUNITY HEALTH / VOL 32 / ISSUE NO 02 / APR - JUN 2020 changes in children aged 6-18 years with body mass index [Internet]. [cited 2020 Mar 29]. Available from: https://sljch.sljol.info/articles/abstract/10.4038/sljch.v47i2.8477/

34. Ballestri S, Nascimbeni F, Baldelli E, Marrazzo A, Romagnoli D, Lonardo A. NAFLD as a Sexual Dimorphic Disease: Role of Gender and Reproductive Status in the Development and Progression of Nonalcoholic Fatty Liver Disease and Inherent Cardiovascular Risk. Adv Ther. 2017 Jun;34(6):1291-1326. doi: 10.1007/s12325-0170556-1. Epub 2017 May 19. Review. PubMed PMID: 28526997; PubMed Central PMCID: PMC5487879.[PubMed].

35. Non Alcholic Fatty Liver Disease (NAFLD) in Overweight and Obese Children - Journal of Clinical and Experimental Hepatology [Internet]. [cited 2020 Mar 29]. Available from: https://www.jcehepatology.com/article/S0973-6883(14)000966/fulltext

36. Ultrasonographic Prevalence Of Non-alcoholic Fatty Liver Disease (nafld) In Kashmir Valley School Children, IJSR - International Journal of Scientific Research(IJSR), IJSR | World Wide Journals [Internet]. [cited 2020 Mar 29]. Available from: https://www.worldwidejournals.com/international-journal-ofscientific-research-(IJSR)/article/ultrasonographic-prevalence-ofnonandndash-alcoholic-fatty-liver-disease-nafld-in-kashmir-valleyschool-children/Njcx/?is=1

37. Carter-Kent C, Brunt EM, Yerian LM, Alkhouri N, Angulo P, Kohli R, Ling SC, Xanthakos SA, Whitington PF, Charatcharoenwitthaya $\mathrm{P}$, Yap J, Lopez R, McCullough AJ, Feldstein AE. Relations of steatosis type, grade, and zonality to histological features in pediatric nonalcoholic fatty liver disease. J Pediatr Gastroenterol Nutr. 2011 Feb;52(2):190-7. doi: 10.1097/MPG.0b013e3181fb47d3. PubMed PMID: 21240012. [PubMed].

38. Mansoor S, Yerian L, Kohli R, Xanthakos S, Angulo P, Ling S, Lopez $\mathrm{R}$, Christine $\mathrm{CK}$, Feldstein $\mathrm{AE}$, Alkhouri $\mathrm{N}$. The evaluation of hepatic fibrosis scores in children with nonalcoholic fatty liver disease. Dig Dis Sci. 2015 May;60(5):1440-7. doi: 10.1007/s10620-014-3494-7. Epub 2014 Dec 25. PubMed PMID: 25540086. [PubMed]

39. Feldstein $\mathrm{AE}$, Charatcharoenwitthaya $\mathrm{P}$, Treeprasertsuk $\mathrm{S}$, Benson $J T$, Enders FB, Angulo P. The natural history of non-alcoholic fatty liver disease in children: a follow-up study for up to 20 years. Gut. 2009 Nov;58(11):1538-44. doi: 10.1136/gut.2008.171280. Epub 2009 Jul 21. PubMed PMID: 19625277; PubMed Central PMCID: PMC2792743.[PubMed]

40. Nobili V, Alisi A, Grimaldi C, Liccardo D, Francalanci P, Monti L, Castellano A, de Ville de Goyet J. Non-alcoholic fatty liver disease and hepatocellular carcinoma in a 7-year-old obese boy: coincidence or comorbidity?. Pediatr Obes. 2014 Oct;9(5):e99e102. doi: 10.1111/j.2047-6310.2013.00209.x. Epub 2013 Dec 3. PubMed PMID: 24302697.[PubMed].

41. Kistler KD, Molleston J, Unalp A, Abrams SH, Behling C, Schwimmer JB. Symptoms and quality of life in obese children and adolescents

\section{Figures}

FIGURE 1 MAPPING THE PREVALENCE OF PAEDIATRIC NAFLD IN INDIA

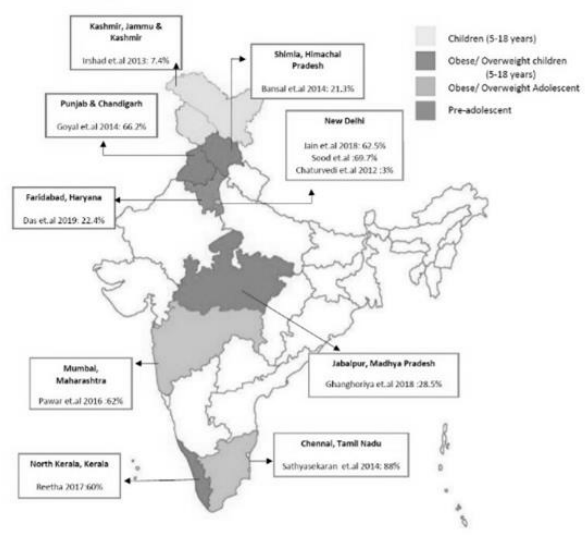

[Non-alcoholic Fatty...] | Rastogi A et al with non-alcoholic fatty liver disease. Aliment Pharmacol Ther. 2010 Feb 1;31(3):396-406. doi: 10.1111/j.13652036.2009.04181.x. Epub 2009 Oct 23. PubMed PMID: 19863497; PubMed Central PMCID: PMC2807909.[PubMed].

42. Kerkar N, D'Urso C, Van Nostrand K, Kochin I, Gault A, Suchy F, Miloh T, Arnon R, Chu J, Annunziato R. Psychosocial outcomes for children with nonalcoholic fatty liver disease over time and compared with obese controls. J Pediatr Gastroenterol Nutr. 2013 Jan;56(1):77-82. doi: 10.1097/MPG.0b013e31826f2b8c. PubMed PMID: 22925921. [PubMed].

43. Sartorio A, Del Col A, Agosti F, Mazzilli G, Bellentani S, Tiribelli C, Bedogni G. Predictors of non-alcoholic fatty liver disease in obese children. Eur J Clin Nutr. 2007 Jul;61(7):877-83. doi: 10.1038/sj.ejcn.1602588. Epub 2006 Dec 6. PubMed PMID: 17151586.[PubMed].

44. Paul J, Venugopal RV, Peter L, Hussain S, Naresh Kumar Shetty K, Shetti MP. Effects of lifestyle modification on liver enzyme and Fibroscan in Indian patients with non-alcoholic fatty liver disease. Gastroenterol Rep (Oxf). 2018 Feb;6(1):49-53. doi: 10.1093/gastro/gox020. Epub 2017 May 17. PubMed PMID: 29479443; PubMed Central PMCID: PMC5806404.[PubMed].

45. Utz-Melere $M$, Targa-Ferreira C, Lessa-Horta B, Epifanio $M$, Mouzaki M, Mattos AA. Non-Alcoholic Fatty Liver Disease in Children and Adolescents: Lifestyle Change - a Systematic Review and Meta-Analysis. Ann Hepatol. 2018 May-June;17(3):345-354. doi: 10.5604/01.3001.0011.7380. Epub 2018 Apr 9. PubMed PMID: 29735796.[PubMed].

46. Gibson PS, Lang S, Dhawan A, Fitzpatrick E, Blumfield ML, Truby H, Hart KH, Moore JB. Systematic Review: Nutrition and Physical Activity in the Management of Paediatric Nonalcoholic Fatty Liver Disease. J Pediatr Gastroenterol Nutr. 2017 Aug;65(2):141-149. doi: 10.1097/MPG.0000000000001624. Review. PubMed PMID: 28737568. [PubMed].

47. Gibson PS, Lang S, Dhawan A, Fitzpatrick E, Blumfield ML, Truby H, Hart KH, Moore JB. Systematic Review: Nutrition and Physical Activity in the Management of Paediatric Nonalcoholic Fatty Liver Disease. J Pediatr Gastroenterol Nutr. 2017 Aug;65(2):141-149. doi: 10.1097/MPG.0000000000001624. Review. PubMed PMID: 28737568. [PubMed].

48. 37014_CE[Ra1]_F(SL)_PF1(MJ_AP)_PFA(MJ_AP)_PN(SHU).pdf [Internet]. [cited 2020 Mar 30]. Available from: https://www.jcdr.net/articles/PDF/12201/37014_CE\%5BRa1\%5D_

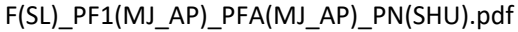

49. Ranjani H, Mehreen TS, Pradeepa R, Anjana RM, Garg R, Anand K, Mohan V. Epidemiology of childhood overweight \& obesity in India: A systematic review. Indian J Med Res. 2016 Feb;143(2):160-74. doi: 10.4103/0971-5916.180203. Review. PubMed PMID: 27121514; PubMed Central PMCID: PMC4859125.[PubMed].

\section{FIGURE 2 PATHO-MECHANISM INVOLVED IN DEVELOPMENT AND PROGRESSION OF NAFLD}

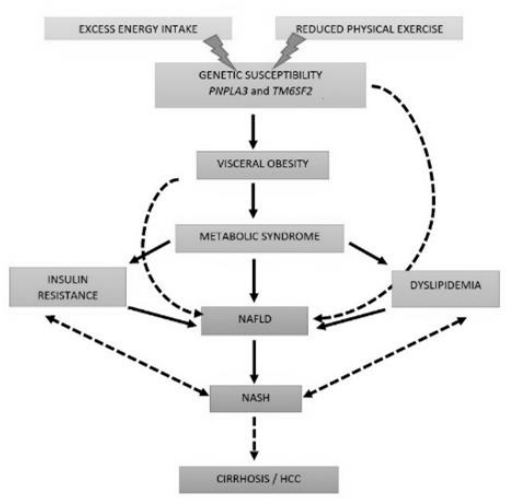

